\title{
Perceived self-efficacy and self-managing of chronic diseases among elderly patients in a clinic setting: how capable are elders in promoting their own health?
}

\author{
Niludi Ranwanee Yasaratna ${ }^{1 *} \&$ MSD Wijesinghe ${ }^{2}$ \\ ${ }^{1}$ Postgraduate Institute of Medicine, University of Colombo, Sri Lanka; ${ }^{2}$ Health promotion Bureau, Ministry \\ of Heath, Sri Lanka
}

*Correspondence: nryasaratna@gmail.com

https://orcid.org/0000-0002-7075-4081

DOI: https://doi.org/10.4038/jccpsl.v25i4.8221

Received on 16 Aug 2019

Accepted on 16 Nov 2019

\begin{abstract}
Introduction: Non-communicable diseases and elderly population are on the rise worldwide. It has created a massive burden on health systems, economies and society. Sri Lanka is no exception. The situation indicates the need for risk factor prevention and control through effective behaviour change programmes. Self-efficacy is postulated as fundamental to achieve behaviour change of individuals to fill the present gap of risk factor control.

Objectives: To assess the perceived self-efficacy in managing chronic diseases to provide an insight into how confident the elderly are in self-managing their diseases

Methods: A hospital-based descriptive cross-sectional study was conducted among elderly patients attending the medical clinic at BH Mulleriyawa. By systematic sampling method, 461 eligible patients diagnosed with one or more five major chronic disease categories were selected. An interviewer-administered chronic disease selfefficacy questionnaire validated for Western countries was used to collect data. Mean perceived self-efficacy score was calculated by adding scores of 10 domains. Adjusted odds ratios (AOR) with $95 \%$ confidence interval (CI) were calculated to find associations with the control of risk factors.

Results: The response rate was $92 \%(n=424)$. The study population had a mean perceived self-efficacy score of $3.64(\mathrm{SD}=0.54)$ out of 5 . The existence of multiple co-morbidities among the elderly was significantly associated with perceived self-efficacy ( $\mathrm{p}=0.02$ ). Respondents with a single disease showed 'good' perceived self-efficacy compared to those with two or more co-morbidities. With respect to disease control status, a statistically significant association was found between 'good' perceived self-efficacy and blood pressure control $(<140 / 90 \mathrm{mmHg})$ $(\mathrm{AOR}=0.47 ; 95 \% \mathrm{CI}=0.24,0.89)$. However, statistically significant associations were not found between blood sugar control $(<110 \mathrm{mg} / \mathrm{dl})$ or total cholesterol level $(<240 \mathrm{mg} / \mathrm{dl})$ with 'good' perceived self-efficacy.

Conclusions: The elderly patients'overall perceived self-efficacy level was found to be well above the average. Targeted interventions to improve self-efficacy may have a beneficial effect on disease control factors such as blood pressure. Further research studies are needed to longitudinally assess the temporality of perceived selfefficacy and its determinants.
\end{abstract}

Keywords: perceived self-efficacy, chronic diseases, elderly 


\section{Introduction}

Sri Lanka has come a long way from its focus on controlling communicable diseases. Currently, chronic non-communicable diseases are overtaking the communicable diseases as the dominant health problem and leading causes of mortality, morbidity and disability in the country. National survey on self-reported health estimated that $17.8 \%$ of the total population has some chronic illness with a prevalence of $45.3 \%$ reported from the age group 60 and above (1). Chronic illness is the most common cause of premature mortality in Sri Lanka and is estimated to cause $80 \%$ of the total burden of disease, mental problems, injury and almost $32.5 \%$ of current health expenditure (2). The illness burden and costs are expected to increase further as the prevalence of chronic illness increases with age. However, it has been estimated that $70-80 \%$ of people living with chronic illness could reduce the illness burden and costs by appropriate self-management (3). This reduction in illness burden is through the associated decrease in hospital admissions, reversed disease progression and halting the development of complications (4).

Increased attention has been focused on chronic disease self-management recently in order to attain patient independence and improve quality of life over the years. Disease management has changed from treatment modality to an approach of holistic health, in which patient plays a significant role in controlling their disease with the guidance of health care providers (5). Most of the chronic diseases like diabetes, heart diseases and chronic respiratory disease though unique in their pathophysiology, share common issues or characteristics in the management. These characteristics include lifestyle adjustment and risk factor control (exercise, diet control, substance use), controlling symptoms and disability, complex drug regimen optimization, coping with psychological and social demands, and effective coordination with the health care providers in follow-up and monitoring of physical indicators (6). Many studies have shown that people with better self-efficacy (7) are managing chronic illness optimally (8-9). This paper aims to assess the perceived self-efficacy and its associations in selfmanaging chronic diseases among elderly patients in a clinic setting to provide insights into effective behaviour change programmes.

\section{Methods}

A hospital-based cross-sectional study was conducted from August to September 2017 at the Base Hospital (BH) Mulleriyawa. This study setting was selected since its medical clinic provides chronic disease management in a holistic manner, which addresses the curative as well as preventive aspects. The study was carried out among elderly patients (60 years and above) with chronic diseases (defined as patients with a diagnosis card of diabetes, ischaemic heart disease, hypertension, hypercholesterolemia, chronic asthma or chronic obstructive pulmonary disease) registered at the medical clinic BH Mulleriyawa. The eligibility criteria of a study unit were diagnosis of one or more of five major chronic diseases for $>1$ year. The sample size of 461 was calculated using a standard formula for a descriptive study (10). The registered list of patients attending the medical clinic on each clinic date was used as the sampling frame and systematic sampling method was used. First patient was selected randomly using a dice and subsequently every third patient was selected. Perceived self-efficacy was assessed by 35-item Perceived Self Efficacy Scale, which was an adapted version of 'Stanford Chronic Disease Self-Management Scale' (11). Face and content validity of the scale was assessed. The questions were categorized according to 10 domains (risk factor control, activities of daily living, social support, recreation, health literacy, health service utility, symptom control, psychological status, complication management and drug compliance). The scale was a Likert scale with five categories. The final score was divided into two categories as 'poor' $(<3.64)$ and 'good' self-efficacy $(>3.64)$ based on the mean of 3.64 .

The disability status was assessed based on questions for impairment of vision, hearing and mobility. In patients with diabetes and hypertension, their disease control status was assessed by averaging the last three month values of fasting blood sugar (cut off was taken as $<110 \mathrm{mg} / \mathrm{dl}$ ) and blood pressure (cut off was taken as $<140 / 90 \mathrm{mmHg}$ ) among those who had the records. Similarly, in hypercholesterolemia, patient's average of total cholesterol value within last six months (cut off was taken as $<240 \mathrm{mg} / \mathrm{dl}$ ) was taken. Statistical significance was taken as $\mathrm{p}$ value $<0.05$ for inferential statistics and logistic regression analysis was performed to find the associations. 


\section{Results}

The response rate was $92 \%(\mathrm{n}=424)$. The mean age of respondents $(\mathrm{n}=424)$ was 69.6 years $(\mathrm{SD}=6.1)$, which ranged from 60 to 89 years. A major of them were females $(n=321 ; 75.7 \%)$; of Sinhalese ethnicity $(\mathrm{n}=408 ; 96.2 \%)$; married and having a living spouse $(n=240 ; 56.6 \%)$. Nearly one-third of the respondents have passed GCE Ordinary Level ( $\mathrm{n}=125 ; 29.5 \%)$, with $85.6 \%(n=363)$ presently unemployed. The distribution of socio-demographic and economic characteristics of the respondents is illustrated in Table 1.

\section{Table 1. Distribution of socio-demographic/ economic characteristics}

\begin{tabular}{lrr}
\hline Characteristics & No. & $\%$ \\
Age & & \\
$60-69$ & 226 & 53.3 \\
$70-79$ & 170 & 40.1 \\
$80-89$ & 28 & 6.6 \\
\hline
\end{tabular}

\begin{tabular}{|c|c|c|}
\hline \multicolumn{3}{|l|}{ Gender } \\
\hline Male & 103 & 24.3 \\
\hline Female & 321 & 75.7 \\
\hline \multicolumn{3}{|l|}{ Ethnicity } \\
\hline Sinhala & 408 & 96.2 \\
\hline Tamil & 6 & 1.4 \\
\hline Muslim & 5 & 1.2 \\
\hline Other & 5 & 1.2 \\
\hline \multicolumn{3}{|l|}{ Religion } \\
\hline Buddhist & 372 & 87.7 \\
\hline Christian & 39 & 9.2 \\
\hline Hindu & 4 & 0.9 \\
\hline Islam & 9 & 2.1 \\
\hline \multicolumn{3}{|l|}{ Marital status } \\
\hline Married (spouse living) & 240 & 56.6 \\
\hline Married (spouse not living) & 161 & 38 \\
\hline Divorced & 12 & 2.8 \\
\hline Unmarried & 11 & 2.6 \\
\hline \multicolumn{3}{|l|}{ Education } \\
\hline No education & 22 & 5.2 \\
\hline Grade 1 - 7 & 78 & 18.4 \\
\hline Grade 8 & 140 & 33 \\
\hline Grade $9-10$ & 20 & 4.7 \\
\hline Passed GCE O/ Level & 125 & 29.5 \\
\hline Passed GCE A/ Level & 31 & 7.3 \\
\hline Postgraduate & 8 & 1.9 \\
\hline
\end{tabular}

Occupation

\begin{tabular}{lrr} 
Presently employed & 61 & 14.4 \\
Presently not employed & 363 & 85.6 \\
\hline Source of income of respondents $^{1}$ & & \\
From children $^{\text {A pensioner }}$ & 193 & 46.3 \\
From employment & 80 & 19.2 \\
From allowances & 62 & 14.9 \\
From properties $^{2}$ & 30 & 7.2 \\
Other $^{2}$ & 7 & 1.7 \\
\hline
\end{tabular}

Gross monthly income of respondents (Rs.)

$\begin{array}{lll}\leq 5,000 & 207 & 48.8\end{array}$

$5,001-10,000 \quad 56 \quad 13.2$

$10,001-15,000 \quad 47 \quad 11.1$

$15,001-20,000 \quad 59 \quad 13.9$

$>20,000 \quad 55 \quad 13.0$

\section{Living with whom ${ }^{3}$}

$\begin{array}{lll}\text { With children } & 298 & 70.6\end{array}$

With spouse only $\quad 74 \quad 17.5$

With relatives $\quad 21 \quad 5.1$

Alone $\quad 28 \quad 6.6$

$\begin{array}{lll}\text { Other }^{4} & 1 & 0.2\end{array}$

${ }^{1}$ Data missing $(\mathrm{n}=7) ;{ }^{2}$ Source of income of relatives or any other persons; ${ }^{3}$ Data missing $(\mathrm{n}=2)$; ${ }^{4}$ Living in an elderly home

With regards to disability status (Table 2), the majority $(n=402 ; 94.8 \%)$ of the study participants were able to walk without support, had normal hearing $(n=399 ; 94.1 \%)$ and could read independently with or without wearing spectacles $(n=407 ; 96 \%)$. The visual impairment was predominant in the respondents compared to mobility and hearing. Only $17.5 \%(n=74)$ were diagnosed with a single disease entity. Majority $(\mathrm{n}=350 ; 82.5 \%)$ had multiple morbidities. The commonest combination was three co-morbidities. The percentage with three or more comorbidities was $52.8 \%(n=157)$.

The overall mean value of perceived self-efficacy was $3.64(\mathrm{SD}=0.54)$. The median was 3.6 and ranged from 2 to 4.83 . Table 3 shows the domains of perceived self-efficacy and percentage below the cut-off (mean value of each domain). According to the scale, a vast majority of respondents reported their self-efficacy as 'poor' in risk factor control (74.8\%), complication management (71.3\%), symptom control (63.7\%), psychological status $(60.2 \%)$ and drug compliance (59.1\%). Almost all respondents reported their selfefficacy was better in activities of daily living (1.4\%) and health service use $(0.7 \%)$ (Table 3 ). 
Table 2. Frequency distribution of disability status and chronic diseases $(\mathrm{N}=424)$

\begin{tabular}{lrr}
\hline Disability & No. & \% \\
\hline Mobility & & \\
Walk Independently & 402 & 94.8 \\
Walk with support & 19 & 4.4 \\
Cannot walk & 3 & 0.7 \\
\hline Hearing & & \\
Can hear normally & 399 & 94.1 \\
Impaired & 25 & 5.9 \\
\hline Vision & & \\
Read well & 153 & 36.0 \\
Read with spectacles & 254 & 60.0 \\
Difficult with spectacles & 14 & 3.3 \\
Can recognize a person & 1 & 0.2 \\
Cannot recognize a person & 2 & 0.5 \\
\hline Chronic disease/s & & \\
Hypertension only & 12 & 2.8 \\
Diabetes only & 167 & 29.7 \\
Ischaemic heart disease only & 8 & 37.0 \\
Hypercholesterolemia only & 8 & 15.8 \\
Chronic lung diseases only & & \\
Two co-morbidities & & \\
Three co-morbidities & & \\
More than three co-morbidities & 6.9 \\
& & \\
\hline
\end{tabular}

In this study, presence of co-morbidities among the elderly was associated significantly with perceived self-efficacy $(p=0.02)$. Respondents with a single disease showed 'good' perceived self-efficacy compared to those with two or more co-morbidities. However, no significant association was found in perceived self-efficacy with recent hospitalizations due to chronic illness $(p=0.2)$. A significant association was evident between perceived self-efficacy and blood pressure control. The participants with 'good' self-efficacy had lower odds of having high blood pressure. The odds for having high total cholesterol and high fasting blood sugar were slightly higher among the 'good' self-efficacy group; however, the results were not significant (Table 4).

\section{Discussion}

The present study found that the overall mean perceived self-efficacy score among elderly patients attending the medical clinic at BH Mulleriyawa was satisfactory. However, the self-efficacy of risk factor control, complication management, symptom control, psychological status and drug compliance were found to be low. Blood pressure level was associated with perceived self-efficacy, while blood sugar and total cholesterol were exceptions that showed no association with perceived self-efficacy.

Table 3. Domains of perceived self-efficacy and percentage below cut-off values

\begin{tabular}{lcccc}
\hline Domain of perceived self-efficacy & \multicolumn{2}{c}{ Scores } & \% below the mean \\
\cline { 2 - 4 } & Maximum & Mean & Median & \\
\hline Risk factor control & 4.63 & 2.2 & 2.25 & 74.8 \\
Activities of daily living & 5 & 4.42 & 4.66 & 1.4 \\
Social support & 5 & 3.52 & 3.5 & 15.6 \\
Recreation & 5 & 3.75 & 4 & 35.7 \\
Health literacy & 5 & 3.55 & 4 & 22.8 \\
Health service utility & 5 & 4.14 & 4.4 & 0.7 \\
Symptom control & 5 & 3.79 & 4 & 63.7 \\
Psychological status & 5 & 4 & 4.2 & 60.2 \\
Complication management & 5 & 3.7 & 4 & 71.3 \\
Drug compliance & 5 & 3.33 & 3.33 & 59.1
\end{tabular}


Table 4. Level of perceived self-efficacy and risk factor control

\begin{tabular}{|c|c|c|c|}
\hline \multirow{2}{*}{$\begin{array}{l}\text { Fasting blood sugar } \\
\text { perceived self-efficacy }^{1}\end{array}$} & \multicolumn{3}{|c|}{$\operatorname{AOR}(95 \% \mathrm{CI})$} \\
\hline & $\begin{array}{l}\text { Blood pressure } \\
>140 / 90 \mathrm{mmHg}\end{array}$ & $\begin{array}{l}\text { Total cholesterol } \\
>240 \mathrm{mg} \mathrm{dl}\end{array}$ & $\begin{array}{c}\text { Fasting blood Sugar } \\
>110 \mathrm{mg} / \mathrm{dl}\end{array}$ \\
\hline Good & $0.47(0.25-0.89)$ & $1.45(0.75-2.82)$ & $1.17(0.67-2.03)$ \\
\hline Poor (Reference) & 1.00 & 1.00 & 1.00 \\
\hline
\end{tabular}

${ }^{1}$ All models were adjusted for age, gender, occupation, education and co-morbidity

There is a growing body of evidence in the world which states that health-related self-efficacy is significantly lower among individuals with greater illness burden compared to their counterparts (12). In the disease profile of this study, many patients were diagnosed with multiple disease entities. The presence of co-morbidity in the study sample was $82.5 \%$. A systematic review done on the prevalence of co-morbidities in South Asia reports that it ranges widely within 4.5\%-83\% (13). Afshar et al. (2015) (14) also reports that co-morbidity is common in low- and middle-income countries and is significantly associated with age. This is consistent with the results of our study. Furthermore, this study also found that with a higher number of co-morbidities, the perceived selfefficacy is rated low.

There is limited literature to support the association of self-efficacy and the risk factor control. Nevertheless, with the limited evidence, our findings are consistent with a study done in the USA, which reported that over half (59\%) who had good selfefficacy were better in managing their hypertension (15). A similar cross-sectional study done on caretakers of Alzheimer patients, high levels of selfefficacy for problem-focused coping were associated with lower mean arterial blood pressure, systolic blood pressure and pulse pressure (16). Some studies have found evidence on the association of self-efficacy with the management of cholesterol level of patients, contrary to what we found in our study. Gaughan (2003) (17) has assessed the self-efficacy as a useful tool for managing eating behaviour change interventions for hypercholesterolemia, which reports a mean self-efficacy of 4.97 for 'heart-healthy eating' associated with low cholesterol level. However, Gaughan's study had only focused on healthy eating, whereas our study had considered multiple risk factors including diet control. The present study did not find any significant association between the perceived selfefficacy and blood sugar control. As an outcome measure of disease control, the fasting blood sugar report may not be a reliable method since it depends on many factors. Furthermore, an actual good glycaemic control can be achieved through a good behavioural approach as well as a change in diet and drugs even in a short-term basis. A more suitable measure would be using $\mathrm{HbAlc}$ test, which was not practical due to the time and resource limitations of the present study. This has been demonstrated in a study done in Myanmar on the prevalence of glycaemic control and its associated factors among diabetic patients, which reports a significant association of high self-efficacy level with good glycaemic control by assessing the glycaemic control using HbA1c (18).

This study was conducted in BH Mulleriyawa, which covers the target population. However, they may not represent the clinic patient populations of other areas of the country. Therefore, the results cannot be generalized to the elderly patient population as a whole. Furthermore, the study design was a cross-sectional design which has the limitation of assessing causative associations between self-efficacy and risk factors. A cohort study design would be best to assess the outcomes of disease control with the continuation of chronic disease self-management programme, which could assess the temporality between perceived selfefficacy and risk factor control. Although maximum efforts were taken to minimize the information bias, the level of perceived self-efficacy was assessed using an interviewer-administered questionnaire, which may have influenced the results. 


\section{Conclusions \& Recommendations}

During the planning and implementation of chronic disease management among elderly patients, particular emphasis should be given to their socio-economic characteristics and social determinants. Assessment of self-efficacy before the initiation of healthy behaviour practices would assist in identifying patients' level of confidence in chronic disease self-management. It will direct the healthy behaviour change programmes to be more focused at individual level, which will lead to achieving better risk factor reduction. In clinics, elderly patients need to be given guidance to improve skills on chronic disease self-management covering all ten domains of the scale holistically. It should be done regularly through a multi-disciplinary team as the elderly are more vulnerable to cognitive impairment. Further research studies should be conducted longitudinally to assess the temporality of perceived self-efficacy and its determinants.

\section{Public Health Implications}

- Self-management of chronic diseases in elderly depends on their level of perceived self-efficacy.

- Level of self-efficacy among elderly is associated with socio economic characteristics and co-morbidities.

- Improving self-managing skills in elderly can improve their level of self-efficacy.

- Healthy behaviour change programmes focusing on perceived self-efficacy will improve self-management of chronic diseases in elderly.

\section{Authors Declarations}

Competing interests: Authors declare that they have no conflicts of interests.

Ethics approval and consent to participate: Ethics approval was granted by the Ethics Review Committee of the Faculty of Medicine, University of Colombo (reference number EC-17-096).

Funding: Self-funded.

Author contributions: NRY conducted the research as principal investigator. MSDW contributed as the technical supervisor of the research project.

\section{References}

1. Department of Census \& Statistics. National Survey on Self-reported Health. Colombo: Ministry of National Policies and Economic Affairs, 2014.

2. Health Economics Cell. Sri Lanka National Health Accounts. Colombo, Ministry of Health, Nutrition \& Indigenous Medicine, 2016.

3. Lorig KR, Sobel DS, Stewart AL, Brown BW, Bandura A, Ritter P, et al. Evidence suggesting that a chronic disease self-management program can improve health status while reducing hospitalization: a randomized trial. Medical Care 1999; 37(1): 5-14.

4. Lorig KR, Sobel DS, Ritter PL, Laurent D, Hobbs M. Effect of a self-management program on patients with chronic disease. Effective Clinical Practice 2001; 4(6): 256-262.

5. Holman $\mathrm{H} \&$ Lorig K. Patients as partners in managing chronic disease. British Medical Journal 2000; 320(7234): 526-527.

6. Wagner EH, Austin BT, Davis C, Hindmarsh M, Schaefer J, Bonomi A. Improving chronic illness care: translating evidence into action. Health Affairs 2001; 20(6): 64-78.

7. Bandura A. Self-Efficacy. Encyclopedia of Human Behavior 1994; 4(1994): 71-81.

8. Daniali SS, Darani FM, Eslami AA, Mazaheri M. Relationship between self-efficacy and physical activity, medication adherence in chronic disease patients. Advanced Biomedical Research 2017; 6: 63.

9. Vellone E, Fida R, D’Agostino F, Mottola A, JuarezVela R, Alvaro R, et al. Self-care confidence may be the key: a cross-sectional study on the association between cognition and self-care behaviors in adults with heart failure. International Journal of Nursing Studies 2015; 52(11): 1705-1713.

10. Charan J \& Biswas T. How to calculate sample size for different study designs in medical research? Indian Journal of Psychological Medicine 2013; 35(2): 121-126.

11. Lorig K, Stewart A, Ritter P, González V, Laurent D, Lynch J. Outcome measures for health education and other health care interventions. Thousand Oaks CA: Sage Publications, 1996.

12. Bradford R, Finney LJ, Jennifer WH, Sauver LS, Wilson P. Health self-efficacy among populations with multiple chronic conditions: the value of patientcentered communications. Advances in Therapy 2016; 33(8): 1440-1451.

13. Pati S, Swain S, Hussain MA, Van Den Akker M, Metsemakers J, Knottnerus JA, et al. Prevalence and outcomes of multimorbidity in South Asia: a systematic review. BMJ Open 2015; 5(10): e007235. 
14. Kowal P, Arokiasamy P, Afshar S, Pati S, Snodgrass JJ. Multimorbidity: health care that counts "past one" for $1 \cdot 2$ billion older adults. Lancet 2015 ; 385(9984): 2252-2253.

15. Warren-Findlow J, Seymour RB, Huber LRB. The association between self-efficacy and hypertension self-care activities among African American adults. Journal of Community Health 2012; 37(1): 12-24.

16. Harmell AL, Mausbach BT, Roepke SK, Moore RC, Von Känel R, Patterson TL, et al. The relationship between self-efficacy and resting blood pressure in spousal Alzheimer's caregivers. British Journal of Health Psychology 2011; 16(2): 317-328.

17. Gaughan ME. Heart healthy eating self-efficacy: an effective tool for managing eating behavior change interventions for hypercholesterolemia. Topics in Clinical Nutrition 2003; 18(4): 229-244.

18. Nyunt SW, Howteerakul N, Suwannapong N, Rajatanun T. Self-efficacy, self-care behaviors and glycemic control among type-2 diabetes patients attending two private clinics in Yangon, Myanmar. Southeast Asian J Trop Med Public Health. 2010; 41(4): 943-951. 